Original Article

\title{
Frequency of Anxiety and Depression among Diabetic Patients and Association with duration of Diabetes Mellitus
}

\author{
Muhammad Ilyas Jat, Abdul Rab Bhutto, Nasir Hussain, Waqas Anwar
}

\begin{abstract}
OBJECTIVE: To determine the frequency of Anxiety and Depression among Diabetic patients and association with duration of Diabetes Mellitus.

METHODOLOGY: Descriptive cross-sectional study conducted at the Out-patient Department (OPD) of Department of Medicine and Allied, Al-Tibri Medical College hospital, Karachi from August 2017 to December 2017. Total 194 patients of both gender with age range from 18 and 70 years suffering from Diabetes Mellitus type 2 were enrolled. The duration of diabetes was taken as less than 5 years, 5-7 years and above 7 years. The frequency of Anxiety and Depression were assessed by Beck Anxiety Inventory and Beck Depression Inventory. The data was analyzed by using SPSS version 20.

RESULTS: The average age of the patients was $50.35 \pm 8.85$. Out of 194 cases $102(52.6 \%)$ were females and $92(47.40 \%)$ were males. Amongst total $(92.80 \%)$ were married. Anxiety was found to be $47(24.2 \%)$ mild to moderate anxiety, $33(17.0 \%)$ suffering from moderate to severe anxiety and $58(29.9 \%)$ were having severe anxiety. Depression was $28(14.4 \%)$ mild depression, $74(38.1 \%)$ moderate depression and $40(20.6 \%)$ severe depression. Statistically depression was significantly associated with duration of diabetes with P-value of 0.000 .

CONCLUSION: It is to be concluded that the frequency of anxiety and depression in patients of Diabetes is very high and depression is significantly associated with duration of Diabetes Mellitus.
\end{abstract}

KEY WORDS: Diabetes Mellitus, Anxiety, Depression.

This article may be cited as: Jat MI, Bhutto AR, Hussain N, Anwar W. Frequency of Anxiety and Depression among Diabetic Patients and Association with duration of Diabetes Mellitus. J Liaquat Uni Med Health Sci. 2018;17(03):170-3. doi: 10.22442/jlumhs.181730572

\section{INTRODUCTION}

The frequency of depression and anxiety in patients having Diabetes Mellitus is impressively higher than normal and varies between 12 to $28 \% \%^{1,2}$. Research has established the link between diabetes duration and anxiety and depression ${ }^{3}$. Anxiety and depression were observed to be $58 \%$ and $45 \%$ of the outpatients with type 2 diabetes respectively, in a recent multicenter study from Pakistan ${ }^{4}$. Both diabetes and anxiety/depression are independently associated with increased morbidity and mortality. Co-event of these conditions adds to the cost, dreariness, and mortality ${ }^{5}$. Both depression and anxiety have been observed to be related with a negative impact on diabetes $^{6}$. It has been accounted for that the patients with diabetes are around twice as liable to experience the Anxiety and Depression as the general population $^{7,8}$. As indicated by confirmations, the relationship between these conditions is bi-directional. It is recognized that patients with both Depression and diabetes, in contrast with diabetic patients alone, have been related with poor self-care and restorative treatment, poorer glycemic control, more diabetes difficulties. Besides, melancholy in diabetes patients is connected with a higher danger of grimness and mortality ${ }^{9}$. It has additionally been watched that both diabetes and Anxiety/depression are related with untimely bleakness and mortality ${ }^{10}$. A recent study has shown the frequency of Depression and Anxiety in patients of Diabetes was $11.5 \%$ and $30.5 \%$ respectively ${ }^{11}$.

Keeping in view the high frequency of anxiety and depression with diabetes this study is designed to see the association of anxiety and depression with duration of diabetes.

\section{METHODOLOGY}

Descriptive cross-sectional study, conducted at the Out-patient Department (OPD) of Department of Medicine and Allied, Al-Tibri Medical College hospital, Karachi from August 2017 to December 2017. Total sample of 194 patients was calculated through standard sample size calculator and non-probability (consecutive) sampling was done. Patients of both gender with age range from 18 and 70 years suffering from Diabetes Mellitus type 2 were included. The duration of diabetes were taken as less than 5 years, 5-7 years and above 7 years. Those patients having established other chronic illnesses such as chronic 
renal disease, Hypo or hyperthyroidism or any other chronic medical condition were excluded from study. Those already diagnosed with Anxiety, Depression or any other psychiatric illnesses were also excluded. The ethical considerations were taken during study and informed consent was taken from clients. Ethical approval was taken from institute ethical committee. There were no any extra charges to diagnose diabetes mellitus, because the subjects were already had positive history of diabetes mellitus and were coming for follow up. For Anxiety and Depression Beck anxiety inventory and Beck depression inventory were used. Mild, moderate and severe forms of Anxiety and Depression were calculated as per score of tools used. The analysis of data was done by using SPSS version 20 .

\section{RESULTS}

A total of 194 Patients diagnosed cases of Diabetes Mellitus having age ranging from 40 to 60 years with average age of $50.35 \pm 8.85$ years were enrolled. Out of 194 cases $102(52.6 \%)$ were females and 92 $(47.40 \%)$ were males. Among total of 194 patients, $180(92.80 \%)$ were married, $6(3.10 \%)$ were single and $8(4.10 \%)$ were widows. Majority of patients were educated till primary and were household or jobless by occupation and Balochi and Urdu speaking ethnicity. Among 194 patients of diabetes, Anxiety as assessed through Beck Anxiety Inventory was found to be 56 $(28.9 \%)$ normal or minimal anxiety, $47(24.2 \%)$ were having mild to moderate anxiety, $33(17.0 \%)$ suffering from moderate to severe anxiety and 58 (29.9\%) were having severe anxiety. Depression as assessed by Beck Depression Inventory was 52 (26.8\%) were normal, $28(14.4 \%)$ were having mild depression, 74 (38.1\%) were of moderate depression and 40 (20.6\%) were suffering from severe depression. Statistically depression was significantly associated with duration of diabetes with p-value of 0.000 while anxiety was insignificantly associated having $p$-value of 0.542 .

TABLE I: DEMOGRAPHIC CHARACTERISTICS OF PARTICIPANTS $(n=194)$

\begin{tabular}{|l|r|}
\hline Demographic Characteristics & \multicolumn{1}{|c|}{$\mathbf{n}(\%)$} \\
\hline Marital status & $06(3.10)$ \\
Single & $180(92.80)$ \\
Married & $08(4.10)$ \\
Widow & \\
Education status & $16(8.20)$ \\
Uneducated & $32(16.50)$ \\
Preliterate & $60(30.90)$ \\
Primary & $22(11.30)$ \\
Middle & $30(15.50)$ \\
Matric & \\
\hline
\end{tabular}

\begin{tabular}{|l|r|}
\hline Intermediate & $14(7.20)$ \\
Graduate & $14(7.20)$ \\
Postgraduate & $06(03.10)$ \\
Occupation status & $72(37.10)$ \\
Jobless & $82(42.30)$ \\
Household & $18(9.20)$ \\
Professional & $22(11.30)$ \\
Shopkeeper & \\
Language & $84(43.30)$ \\
Balochi & $12(06.20)$ \\
Pashto & $12(06.20)$ \\
Punjabi & $40(20.60)$ \\
Sindhi & $46(23.70)$ \\
Urdu & \\
\hline
\end{tabular}

TABLE II: FREQUENCY OF ANXIETY AND DEPRESSION AMONG PATIENTS OF DIABETES AS PER BECK DEPRESSION INVENTORY AND BECK ANXIETY INVENTORY

\begin{tabular}{|l|c|}
\hline \multicolumn{1}{|c|}{ Anxiety as per BAl } & $\mathbf{n} \%$ \\
\hline 0-9: normal to minimal anxiety & $56(28.9 \%)$ \\
\hline 10-18: mild to moderate anxiety & $47(24.2 \%)$ \\
\hline 19-29: moderate to severe anxiety & $33(17.0 \%)$ \\
\hline 30-63: severe anxiety & $58(29.9 \%)$ \\
\hline Total & $194(100 \%)$ \\
\hline \multicolumn{1}{|c|}{ Depression as per BDI score } & $\mathbf{n} \%$ \\
\hline Normal 1-16 score & $52(26.8 \%)$ \\
\hline Mild 17-20 & $28(14.4 \%)$ \\
\hline Moderate 21-30 & $74(38.1 \%)$ \\
\hline 31 and above severe & $40(20.6 \%)$ \\
\hline Total & $194(100 \%)$ \\
\hline
\end{tabular}

\section{DISCUSSION}

In this study it was observed that the frequency of depression among patients of diabetes mellitus from mild to severe level was $14.4 \%, 38.1 \%$ and $20.6 \%$ respectively and anxiety was found to be from mild to severe as $24.2 \%, 17.0 \%$ and $29.9 \%$ respectively. It is slightly greater than the study published in 2015 which showed the frequency of depression and anxiety among diabetes patients as having the depression from mild to severe level $(10.8 \%, 24.6 \%$ and $12.5 \%$ respectively) and anxiety from mild to severe level $(4.6 \%, 27.9 \% \text { and } 37.1 \% \text { respectively })^{12}$. In Qatar, a study was conducted on diabetic patients and it was observed that $13.6 \%$ of diabetes patients had severe depression, $35.3 \%$ had severe anxiety while in our study the level of severe depression and anxiety is 
Muhammad Ilyas Jat, Abdul Rab Bhutto, Nasir Hussain, Waqas Anwar

TABLE III: ASSOCIATION OF DEPRESSIVE DISORDER WITH DURATION OF DIABETES

\begin{tabular}{|l|r|r|r|r|r|r|}
\hline \multirow{2}{*}{ Duration of Diabetes } & \multicolumn{4}{|c|}{ Depressive Disorder } & \multirow{2}{*}{ Total } & \multirow{2}{*}{ P-Value } \\
\cline { 2 - 5 } & \multicolumn{1}{|c|}{ Normal } & \multicolumn{1}{|c|}{ Mild } & Moderate & Severe & & \\
\hline Less than 5 years & $32(43.2 \%)$ & $18(24.3 \%)$ & $14(18.9 \%)$ & $10(13.5 \%)$ & $74(100 \%)$ & \\
\cline { 1 - 5 } 5-7 years & $4(8.3 \%)$ & $0(0 \%)$ & $30(62.5 \%)$ & $14(29.2 \%)$ & $48(100 \%)$ & \multirow{0}{*}{0.000} \\
\hline Above 7 years & $16(22.2 \%)$ & $10(13.9 \%)$ & $30(41.7 \%)$ & $16(22.2 \%)$ & $72(100 \%)$ & \\
\hline Total & $52(26.8 \%)$ & $28(14.4 \%)$ & $74(38.1 \%)$ & $40(20.6 \%)$ & $194(100 \%)$ & \\
\hline
\end{tabular}

TABLE IV: ASSOCIATION OF ANXIETY DISORDER WITH DURATION OF DIABETES

\begin{tabular}{|l|r|r|r|r|r|r|}
\hline \multirow{2}{*}{ Duration of Diabetes } & \multicolumn{4}{|c|}{ Anxiety Disorder } & \multirow{2}{*}{ Total } & \multirow{2}{*}{ P-Value } \\
\cline { 2 - 5 } & $\begin{array}{c}\text { Normal or } \\
\text { minimal anxiety }\end{array}$ & $\begin{array}{c}\text { Mild to mod- } \\
\text { erate anxiety }\end{array}$ & $\begin{array}{c}\text { Moderate to } \\
\text { severe anxiety }\end{array}$ & Severe anxiety & & \\
\hline Less than 5 years & $19(25.7 \%)$ & $17(23.0 \%)$ & $17(23.0 \%)$ & $21(28.4 \%)$ & $74(100 \%)$ & \\
\hline 5-7 years & $18(37.5 \%)$ & $12(25.0 \%)$ & $6(12.5 \%)$ & $12(25.0 \%)$ & $48(100 \%)$ & \multirow{0}{*}{$\mathbf{5 1 0}$} \\
\hline Above 7 years & $19(26.4 \%)$ & $18(25.0 \%)$ & $10(13.9 \%)$ & $25(34.7 \%)$ & $72(100 \%)$ & \\
\hline Total & $56(28.9 \%)$ & $47(24.2 \%)$ & $33(17.0 \%)$ & $58(29.9 \%)$ & $194(100 \%)$ & \\
\hline
\end{tabular}

$20.6 \%$ and $29.9 \%$ respectively, here the level of severe depression is more as compared to previous but anxiety is less, the differences could be many as methodology, psychosocial circumstances etc ${ }^{13}$.

A study conducted to observe the occurrence of depression in patients of diabetes and concluded that $44.5 \%$ diabetes patients had no depression, $24.5 \%$ had mild depression, $25.5 \%$ had moderate depression and $5.5 \%$ had severe depression on the Beck Depression Inventory (BDI) ${ }^{14}$ while in our study we also had applied the same tool but the results are different as $26 \%$ had no depression while from mild to severe was $14.4 \%, 38.1 \%$ and $20.6 \%$ respectively, the difference could be due the previous study was conducted at Baskent University Istanbul Hospital Turkey ${ }^{14}$ which is a developed country and our study is from a low socioeconomic area of Karachi, Pakistan where Pakistan is considered as "Third World Country". A study conducted in India had shown the frequency of depression among diabetic patients as $26.3 \%$ and anxiety as $27.6 \%{ }^{15}$ while in our study the severe depression was $20.6 \%$ and severe anxiety as $29.9 \%$, the difference could be due that they had used Hamilton anxiety and depression scale while we have used BDI (Beck depression inventory). A study had shown that $50 \%$ of clients attending diabetic clinic were observed having anxiety and depression while we have seen more than $50 \%$ diabetic patients having anxiety and depression, hence the variability of frequency of depression and anxiety in diabetic population has been observed. In our study depression has been linked significantly with duration of diabetes while anxiety is not linked, while in another study from Pakistan has shown that duration of diabetes has little effects on both anxiety and depression ${ }^{16}$.

\section{CONCLUSION}

It is concluded that the frequency of Anxiety and Depression in patients of Diabetes Mellitus is very high and Depression is significantly associated with its duration of Diabetes.

Therefore management of Diabetes as well as Anxiety and Depression should be done as earlier as possible to reduce the morbidity and mortality.

\section{ACKNOWLEDGMENT}

We wish to extend our heartfelt gratitude to computer operator Mr. Aqeel Ahmed for his efforts throughout this research work.

\section{REFERENCES}

1. Hermanns N, Scheff C, Kulzer B, Weyers P, Pauli $\mathrm{P}$, Kubiak $\mathrm{T}$, et al. Association of glucose levels and glucose variability with mood in Type 1 diabetic patients. Diabetologia 2007; 50(5):930-3.

2. Shaban MC, Fosbury J, Kerr D, Cavan DA. The prevalence of depression and anxiety in adults with Type 1 diabetes. Diabet Med 2006; 23 (12):1381-4.

3. Anderson RJ, Freedland KE, Clouse RE, Lustman PJ. The prevalence of co-morbid depression in adults with diabetes: A meta-analysis. Diabetes Care 2001; 24(6):1069-78. 
4. Khuwaja AK, Lalani S, Dhanani R, Azam IS, Rafique G, White F. Anxiety and depression among outpatients with type 2 diabetes: A multi-centre study of prevalence and associated factors. Diabetol Metab Syndr 2010; 2:72. doi: 10.1186/1758-5996-2-72. .

5. Lin $\mathrm{EH}$, Rutter CM, Katon W, Heckbert SR, Ciechanowski P, Oliver MM, et al. Depression and advanced complications of diabetes: A prospective cohort study. Diabetes Care 2010; 33 (2):264-9. doi: 10.2337/dc09-1068.

6. Prisciandaro JJ, Gebregziabher M, Grubaugh AL, Gilbert GE, Echols C, Egede LE. Impact of psychiatric comorbidity on mortality in veterans with type 2 diabetes. Diabetes Technol Ther 2011; 13 (1):73-8. doi: 10.1089/dia.2010.0092.

7. Nichols GA, Brown JB. Unadjusted and Adjusted Prevalence of Diagnosed Depression in Type 2 Diabetes. Diabetes Care 2003;26(3):744-749.

8. Knol MJ, Heerdink ER, Egberts AC, Geerlings MI, Gorter KJ, Numans ME, et al. Depressive symptoms in subjects with diagnosed and undiagnosed type 2 diabetes. Psychosom Med 2007;69(4):300-5.

9. Roupa Z, Koulouri A, Sotiropoulou P, Makrinika E, Marneras X, Lahana I, et al. Anxiety and depression in patients with type 2 diabetes mellitus, depending on sex and body mass index. Health Sci J 2009; 3(1):32-40.

10. Kohei K. Pathophysiology of Type 2 Diabetes and
Its Treatment Policy. JMAJ 2010; 53(1):41-6.

11. Kaur G, Tee GH, Ariaratnam S, Krishnapillai AS, China K. Depression, anxiety and stress symptoms among diabetics in Malaysia: a cross sectional study in an urban primary care setting. BMC Fam Pract 2013; 14(1):69. doi: 10.1186/1471-2296-14-69.

12. Rehman A, Kazmi SF. Prevalence and Level of Depression, Anxiety and Stress among Patients with Type-2 Diabetes Mellitus. Ann. Pak. Inst. Med. Sci 2015; 11(2): 81-6.

13. Bener A, Al-Hamaq AOAA, Dafeeah EE. High prevalence of depression, anxiety and stress symptoms among diabetes mellitus patients. Open Psychiatry J 2011; 5:5-12.

14. Parildar H, Cigerli O, Demirag NG. Depression, coping strategies, glycemic control and patient compliance in type 2 diabetic patients in an endocrine outpatient clinic. Pak J Med Sci 2015; 31(1):19-24. doi: 10.12669/pjms.311.6011.

15. Rajput R, Gehlawat P, Gehlan D, Gupta R, Rajput $M$. Prevalence and predictors of depression and anxiety in patients of diabetes mellitus in a tertiary care center. Indian J Endocrinol Metab 2016; 20 (6):746-751.

16. Azad N, Gondal M, Abbas N, Shahid A. Frequency of depression and anxiety in patients attending a diabetes clinic. J Ayub Med Coll Abbottabad 2014; 26(3):323-7.

\section{垱}

AUTHOR AFFILIATION:
Dr. Muhammad Ilyas Jat (Corresponding Author)
Assistant Professor, Department of Psychiatry
Isra University Karachi Campus, Al-Tibri, Medical College
Malir, Karachi, Sindh-Pakistan.
Email: ilyas.jat84@gmail.com
Dr. Abdul Rab Bhutto
Assistant Professor
Department of Medicine and Allied
Isra University Karachi Campus, Al-Tibri, Medical College
Malir, Karachi, Sindh-Pakistan.
Dr. Nasir Hussain
House Officers
Department of Medicine and Allied
Isra University Karachi Campus, Al-Tibri, Medical College
Malir, Karachi, Sindh-Pakistan.
Dr. Waqas Anwar
House Officers
Department of Medicine and Allied
Isra University Karachi Campus, Al-Tibri, Medical College
Malir, Karachi, Sindh-Pakistan.

